\title{
A simple NMR methodology for evaluating filter cake properties and drilling fluid-induced formation damage
}

\author{
Abdulrauf R. Adebayo' ${ }^{1}$ - Badr S. Bageri² \\ Received: 26 May 2019 / Accepted: 21 September 2019 / Published online: 3 October 2019 \\ (c) The Author(s) 2019
}

\begin{abstract}
An efficient drilling fluid will form a filter cake that will minimize the drilling fluid invasion into any drilled formation. Drilling fluid must therefore be adequately evaluated in the laboratory prior to field trial. Filter cake properties such as thickness, porosity, permeability, and pore structure are frequently evaluated using several techniques such as CT scan, SEM, and XRF. However, each of these techniques can evaluate only one or two filter cake properties. This paper presents a simple but novel NMR technique to evaluate filter cake properties such as thickness, pore volume, porosity, and possibly permeability. Furthermore, the amount and particle size distribution of solids that invaded a given rock sample can be obtained using the same technique. The full procedure was tested and verified using four identical rock samples. Drilling fluid invasion and filter cake deposition experiments were conducted on each of the samples, using the same drilling fluid but four different concentrations of fluid loss additive. NMR $T_{2}$ relaxation measurements were taken at three different stages of each rock sample: before filter cake deposition; after fluid invasion and filter cake deposition; and after filter cake removal. A material balance analysis of the probability density function and cumulative distribution function of the measured $T_{2}$ profile at the different stages of each sample yielded multiple filtration loss properties of the filter cake. The results obtained showed high accuracy of the NMR versus the current techniques. Moreover, this current method evaluated the majority of the filter cake properties at the same time and in situ hence eliminated the need of using multi-procedures that disturb the sample state. Finally, the presented method can also be used to evaluate secondary damage associated with filter cake removal process.
\end{abstract}

Keywords Filter cake characterization $\cdot$ Drilling fluid $\cdot$ Formation damage $\cdot$ NMR $\cdot$ CT scan

\section{Introduction}

Formation damage impairs well deliverability, injectivity, drainage efficiency, and ultimately hydrocarbon recovery. Formation damage can be caused by many operational factors such as clay swelling, fine migration and deposition, particle invasion, and plugging during drilling operations. Amaefule et al. (1988) classified frequently encountered formation damage mechanisms into two broad categories. The first category is the damage caused by fluid-fluid interactions (e.g., emulsion blocking and organic and inorganic

Abdulrauf R. Adebayo

abdulrauf@kfupm.edu.sa

1 Center for Integrative Petroleum Research, King Fahd University of Petroleum and Minerals, Dhahran, Saudi Arabia

2 Department of Petroleum Engineering, King Fahd University of Petroleum and Minerals, Dhahran, Saudi Arabia deposition). The second category involves damage caused by rock-fluid interaction. Examples include mobilization and relocation of in situ rock fine particles, invasion and deposition of ex situ fine particles, alteration of rock properties by surface processes like wettability change, swelling, adsorption, and desorption. Reservoir rocks are exposed to external fluids at different stages of their life via wells drilled through them. The source of such damaging particles can be from fluids used in different operations such as drilling, cementing, completion and workover, hydraulic fracturing. The mechanism of formation damage depends on the reservoir conditions, the nature of the rock, and fluids involved.

Drilling fluid invasion during well drilling is usually the first source of formation damage. Although minimal and shallow particle invasion is required for filter cake deposition over the face of the drilled formation, uncontrolled and unrestricted invasion of these particles can have an adverse effect in the near-wellbore region. The formation permeability can be significantly reduced such that future or enhanced

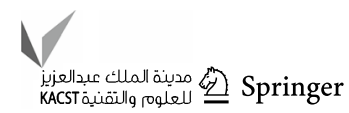


hydrocarbon production processes may be impaired. The depth of particle invasion and deposition depend on the concentration of the particle in the drilling fluid, particle size distribution, and the drilling fluid rheology (Offenbacher et al. 2013). In order to minimize the formation damage, laboratory experiments are used to optimize the composition of external fluids that are intended to be injected into a formation. In addition, experiments are required to optimize the particle concentration and size distribution of the fluid.

Experimental studies should be able to provide meaningful and accurate data on formation damage. Such data can be used to either develop or validate mathematical models, which can also be used to develop efficient mitigation strategies against formation damage (Civan 2007). Different approaches have been reported for evaluating formation damage. Formation damage can be evaluated by measuring the permeability of a representative rock sample at simulated reservoir conditions prior to and after formation damage, where damage is characterized by permeability reduction (Gabriel and Inamdar 1983; Civan 2016). X-ray computer tomography has also been used to evaluate formation damage (e.g., Krilov et al. 1991; Seright and Prodanovic 2006). Some researchers have also reported the use of scanning electron microscope (SEM) to study fines deposition at the nanometer or micrometer scale (e.g., Kandarpa and Sparrow 1981; Byrne et al. 2000; Green et al. 2013). All of these methods are indirect, and they neglect transient nature of formation damage. High-resolution imaging methods like SEM and X-ray CT are complex and time-consuming. They can also be intrusive because of the need to cut and polish the samples (Bageri et al. 2013). They are also not suitable to study fast processes (Godinho et al. 2019). Furthermore, frequent sample handling can cause changes in filter cake properties and hence introduce measurement errors. Few researchers reported the use of nuclear magnetic resonance to probe the changes in the pore sizes of rocks (e.g., Tran et al. 2010; Fischer et al. 2011; Al-Yaseri et al. 2015). The major advantage of NMR method is that formation damage can be investigated in situ and at pore-scale resolution. NMR measurements can be taken with minimal sample handling. Any developed NMR methodology can also be implemented downhole in the reservoir during the drilling process. This is crucial for in situ and real-time damage assessment and for an effective appraisal of the mitigation strategy. So far, the reported NMR methodology in the literature only investigated the changes in pore structure of the rocks, with insufficient information about the filter cake and invaded mud particles.

In this paper, a simple and novel NMR procedure is presented that can be implemented in the laboratory and in the field during drilling operations. In this analytical method, formation damage was evaluated in terms of pore size distribution, volume and particle size distribution of the invaded drilling fluid. The volume and particle size distribution of the filter cake are also determined. All these parameters can be obtained as a function of time. This study does not aim to investigate a specific subsurface reservoir or well. It only seeks to exploit an improved methodology, which can give a useful and meaningful data. Hence, some important factors were not considered in this proof-of-concept study such as heterogeneity of rock, wettability, need to use preserved rock samples (or samples with restored state), and other factors that affect the representativeness of actual reservoir condition (as carefully noted by Bennion et al. 1991). In a specific field study, these factors need to be considered when implementing this methodology.

\section{Methodology}

The methodology covers the use of NMR measurements to evaluate filtration properties of drilling fluid and the formation damage arising from filtration.

\section{Rock samples}

A 10 -in. $(25.4 \mathrm{~cm})$ long by 1.5 -in. $(3.792 \mathrm{~cm})$ cylindrical rock samples extracted from a carbonate outcrop was cut into four identical pieces as shown in Table 1. NMR analysis of the four samples shows that they are relatively homogeneous with very similar pore structure as shown in Fig. 1.

\section{Drilling fluids}

The composition of drilling fluid is presented in Table 2. A barite-weighted water-based drilling fluid system was used

Table 1 Rock samples

\begin{tabular}{llllll}
\hline Sample ID & Mineralogy & Diameter $(\mathrm{cm})$ & Length $(\mathrm{cm})$ & Porosity $(\%)$ & $\begin{array}{l}\text { Helium } \\
\text { permeability } \\
(\mathrm{mD})\end{array}$ \\
\hline Sample 1 & Carbonate & 3.792 & 5.08 & 17.5 & 84 \\
Sample 2 & Carbonate & 3.792 & 5.06 & 17.5 & 80 \\
Sample 3 & Carbonate & 3.792 & 5.03 & 15.8 & 70 \\
Sample 4 & Carbonate & 3.792 & 5.02 & 16.7 & 76 \\
\hline
\end{tabular}




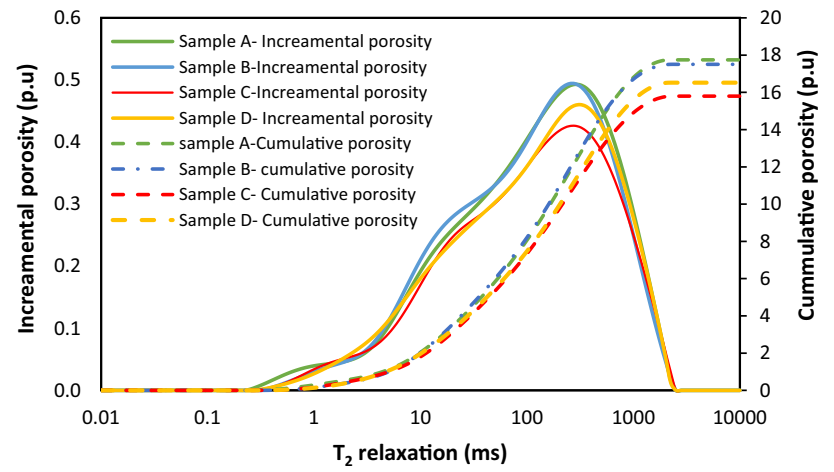

Fig. 1 NMR $T_{2}$ relaxation for all samples. Continuous lines show the probability distribution function (PDF) of the pores (pore size distribution of the samples), while the broken lines show the cumulative distribution function (CDF) of their porosity

in this study. Four different samples of the drilling fluid were prepared in the laboratory based on the compositions shown in Table 2. The first formulation serves as the base or reference fluid. The other three drilling fluids have the same composition as the base fluid except that each of them has varying concentrations of fluid loss additive (called silica). As shown in the table, drilling fluid \#2 contains $1 \mathrm{wt} \%$ of the additive, drilling fluid \#2 contains $2 \mathrm{wt} \%$, and drilling fluid \#3 contains $3 \mathrm{wt} \%$. The added additives have been shown in the literature to be capable of improving the sealing characteristics of the filter cake layer and greatly prevent solid invasion into the rock formation. Since the rock samples under investigation are of the same type and are to a large extent homogeneous, comparison can be fairly made between the performance evaluation of the filter cake and formation invasion profiles.

\section{Equipment and procedure}

A customized filtration loss setup (Fig. 2) was designed to be able to accommodate approximately 5 -cm-long rock sample. The setup comprises a stainless-steel cylinder having two detachable end caps. The end caps have flow-through and pressure ports, which allow monitoring of fluid flow and differential pressure, respectively. A backpressure of $200 \mathrm{psi}$ was applied to the outlet of the test cell. The test sample was pre-saturated with $5 \%$ potassium chloride solution $(\mathrm{KCl})$ and then loaded into the test cell. The rock sample was embedded in a hollow rubber sleeve such that one end of the sample was opened to the outlet cap of the cell and the other end is exposed to the content of the test cell. The drilling fluid was then poured on the surface of the core sample and allowed to rise to form a vertical column of drilling fluid. Heat was then gradually applied to the cell until the test temperature reached $150^{\circ} \mathrm{F}$. Nitrogen gas was then applied over the fluid column to apply a hydrostatic pressure of $500 \mathrm{psi}$ across the sample such that the differential pressure across the sample was $300 \mathrm{psi}$. The pressure and temperature were monitored and regulated to maintain a constant value throughout the test. Fluid loss at the outlet of the test cell was also monitored. The experiment was terminated after 30 min (standard API time for fluid loss test). The cell pressure and temperature were then gradually lowered, and the sample was carefully retrieved to avoid deformation of the deposited filter cake on the face of the samples. The rubber sleeve ensured that filtration loss only occurs through the axial direction (top to bottom). This allowed the filter cake to be deposited on the cross-sectional area of the sample. The retrieved sample, with filter cake on the top (Fig. 3A), was immediately loaded in a tight seal glass vessel for NMR
Table 2 Drilling fluid formulation

\begin{tabular}{|c|c|c|c|c|c|}
\hline \multirow[t]{2}{*}{ Chemical composition } & \multirow[t]{2}{*}{ Unit } & \multirow{2}{*}{$\begin{array}{l}\text { Drilling fluid } \\
\# 1 \text { based fluid } \\
\text { Description }\end{array}$} & \multirow{2}{*}{$\begin{array}{l}\text { Drilling fluid \#2 } \\
\text { Description }\end{array}$} & \multirow{2}{*}{$\begin{array}{l}\text { Drilling fluid \#3 } \\
\text { Description }\end{array}$} & \multirow{2}{*}{$\begin{array}{l}\text { Drilling fluid \#4 } \\
\text { Description }\end{array}$} \\
\hline & & & & & \\
\hline Water & bbl & 0.691 & 0.691 & 0.691 & 0.691 \\
\hline Bentonite & $\mathrm{lb}$ & $4-6$ & $4-6$ & $4-6$ & $4-6$ \\
\hline $\mathrm{XC}$ polymer & $\mathrm{lb}$ & 0.5 & 0.5 & 0.5 & 0.5 \\
\hline BARANEX & $\mathrm{lb}$ & 0.3 & 0.3 & 0.3 & 0.3 \\
\hline $\mathrm{KCl}$ & $\mathrm{lb}$ & 20.0 & 20.0 & 20.0 & 20.0 \\
\hline $\mathrm{KOH}$ & $\mathrm{lb}$ & 0.5 & 0.5 & 0.5 & 0.5 \\
\hline $\mathrm{NaCl}$ & $\mathrm{lb}$ & 66 & 66 & 66 & 66 \\
\hline Barite & $\mathrm{lb}$ & 352.0 & 352.0 & 352.0 & 352.0 \\
\hline $\mathrm{CaCO}_{3}$ medium & $\mathrm{lb}$ & 5.0 & 5.0 & 5.0 & 5.0 \\
\hline Sodium sulfite & $\mathrm{lb}$ & 0.30 & 0.30 & 0.30 & 0.30 \\
\hline Soltex & $\mathrm{lb}$ & $1.0-2.0$ & $1.0-2.0$ & $1.0-2.0$ & $1.0-2.0$ \\
\hline BlackNite & Gal & $0.3-0.5$ & $0.3-0.5$ & $0.3-0.5$ & $0.3-0.5$ \\
\hline SOURSCAV & $\mathrm{lb}$ & 2 & 2 & 2 & 2 \\
\hline Additive (silicate) & $\mathrm{lb}$ & 0 & 1.0 & 2.0 & 3.0 \\
\hline
\end{tabular}




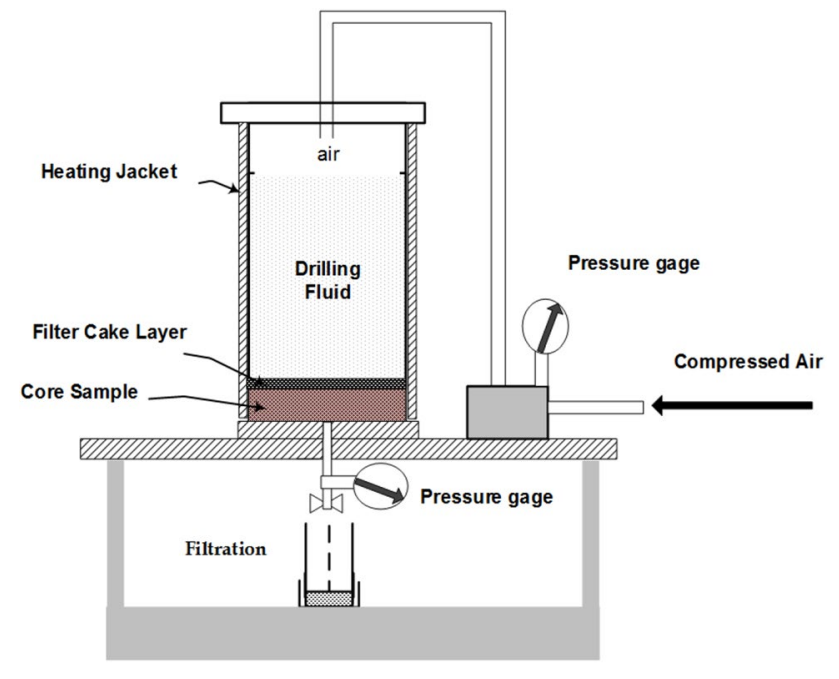

Fig. 2 Assembled high-pressure high-temperature fluid loss system to form filter cake

relaxometry experiments. At the end of the NMR measurements, the filter cake was removed by carefully wiping it off the rock sample. After filter cake removal, the surface area of the rock sample was gently rinsed with the same $\mathrm{KCl}$ brine in order to remove the remnant filter cake, and NMR measurements were taken again. Figure 3B shows the flowchart of the experimental procedure.

In NMR relaxometry, $T_{2}$ relaxation is a measure of the time it takes a hydrogen molecule (or proton) to relax back to its natural direction of precession after it was excited by a magnetic field in a direction transverse (perpendicular) to the magnetic field. $T_{2}$ relaxation is measure in milliseconds (ms), and it is related to surface-to-volume ratio of the pores and the surface relaxivity $(\rho)$ of the rock minerals lining the pore surface. $T_{2}$ measurements are taken in NMR equipment using a special pulse sequence called CPMG named after the inventors, Carr and Purcell (1954) and Meiboom and Gill (1958).

A low-magnetic-field NMR (0.05 Tesla or $2 \mathrm{MHz}$ ) GeoSpec rock core analyzer from Oxford Instruments was used to measure $T_{2}$ relaxation of the samples and spatial $T_{2}$ along the sample length, using optimized scanning parameters as follows: Tau value of $0.1 \mathrm{~ms}$; signal-to-noise ratio of 200; and recycle delay of $11,250 \mathrm{~ms}$. For the spatial $T_{2}$ measurements, the samples were segmented into 20 slices with a tau value of $0.1 \mathrm{~ms}$ and a recycle delay of $450 \mathrm{~ms}$. The average scanning time was 15 min per sample. The NMR system is equipped with a user-friendly GIT (green imaging technology) software package, which was used for setting up scanning parameters and data processing. NMR measurements were taken at three different stages, namely a baseline/initial NMR profile (only rock), NMR profile after filter cake deposition and mud invasion (rock + filter cake + mud filtrate), and NMR profile after filter cake has been removed (rock + mud filtrate). Each sample was initially saturated with $5 \% \mathrm{KCl}$ brine, and the base (initial) $\mathrm{NMR} T_{2}$ profile was measured for each sample. Figure 4 shows the experimental setup for the NMR relaxometry tests.

The internal structure of each rock sample at pre- and post-drilling fluid invasion was also examined using crosssectional digital imaging obtained over the full length of each sample with an X-ray medical CT-scanner model TSX032A. Each sample was scanned at 1-mm slice thickness and 1 -mm slice interval using a power of $20 \mathrm{kV}$ and $300 \mathrm{~mA}$.
Fig. 3 A Rock sample with filter cake deposited on the surface area and $\mathbf{B}$ flowchart of experimental procedure

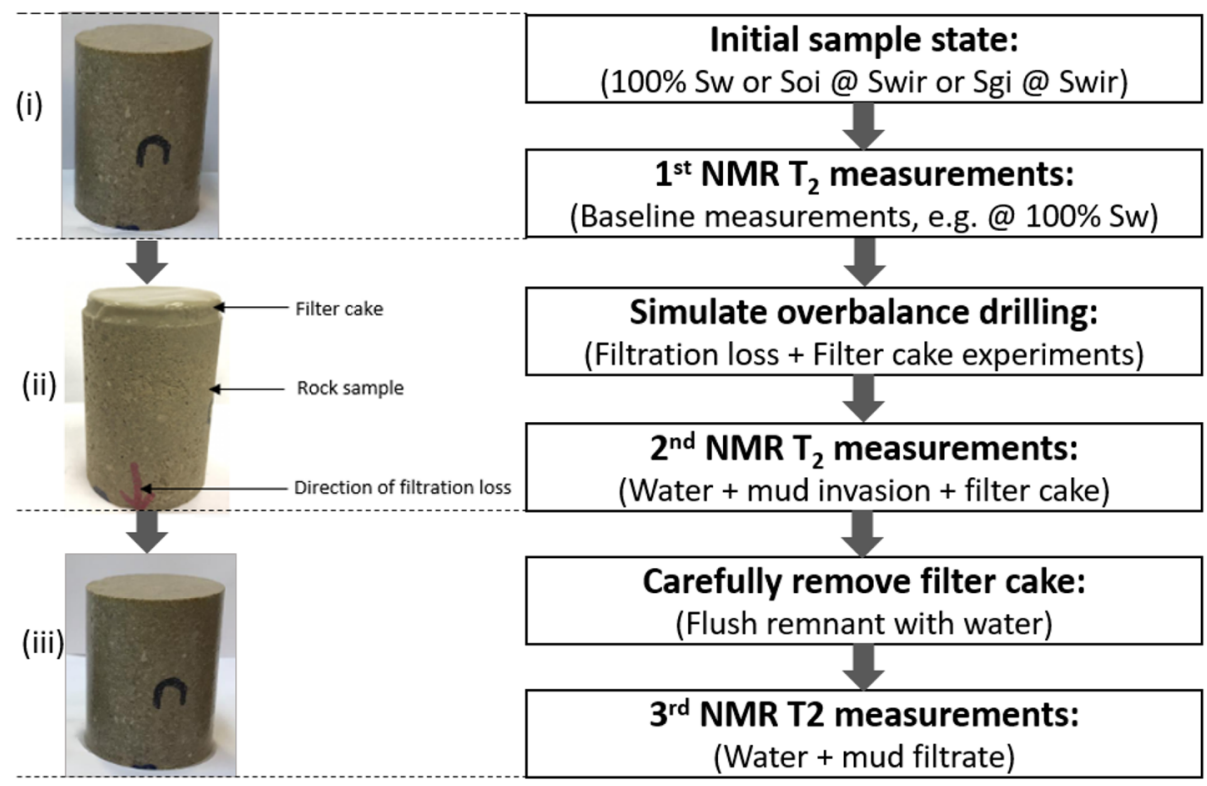

(A) 
Fig. 4 NMR setup for rock sample with filter cake on it

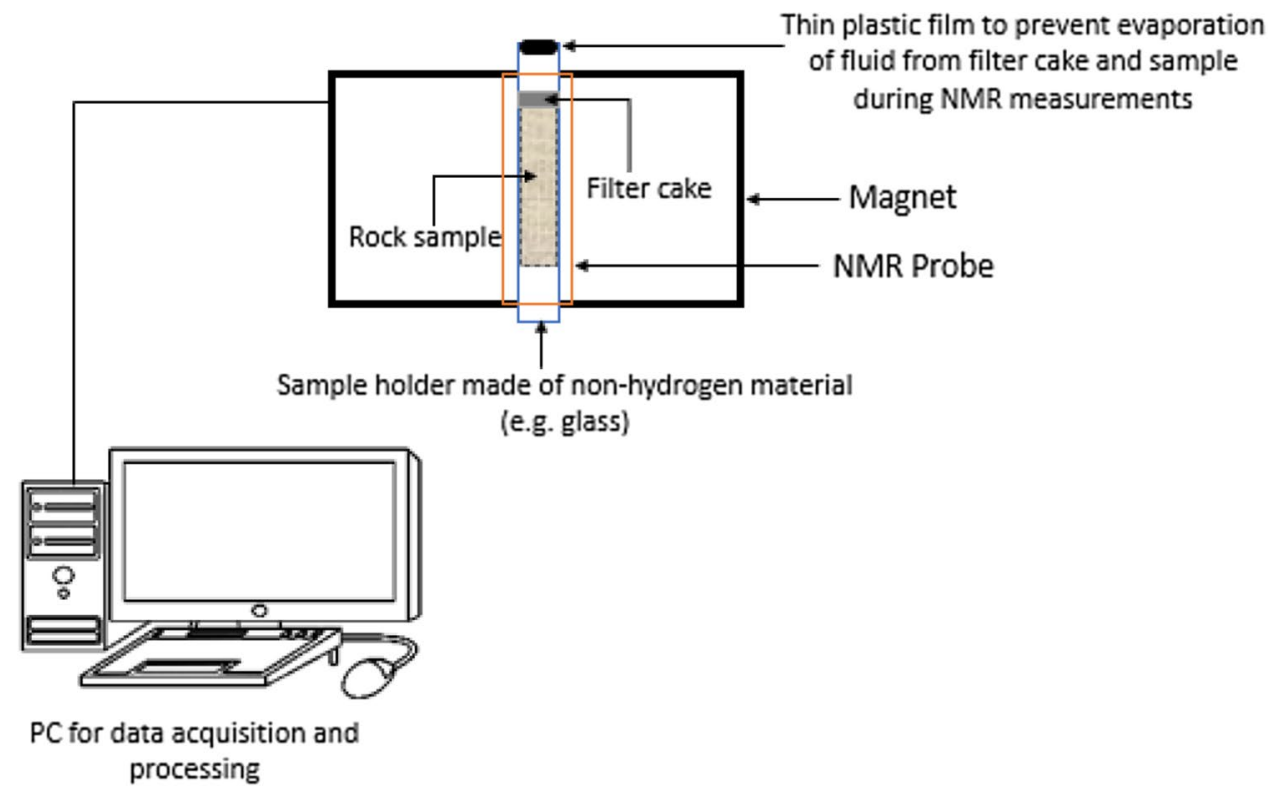

\section{Results and discussion}

In the first experiment, which was conducted on the reference sample-1, the additive (silica) was not added to the drilling fluid. The CT scan of slices prior to mud invasion is shown in Fig. 5 (left), while the CT scan of the same sample after mud invasion is shown on the right of the same figure. The gray scale at the bottom of the figure represents the density and CT number distribution in the slices, with the gray becoming lighter as the $\mathrm{CT}$ number or density increases. A separate color (pink) was included to represent the density $(4.48 \mathrm{~g} / \mathrm{cc})$ and CT number of barite and therefore was excluded from the histogram. Hence,
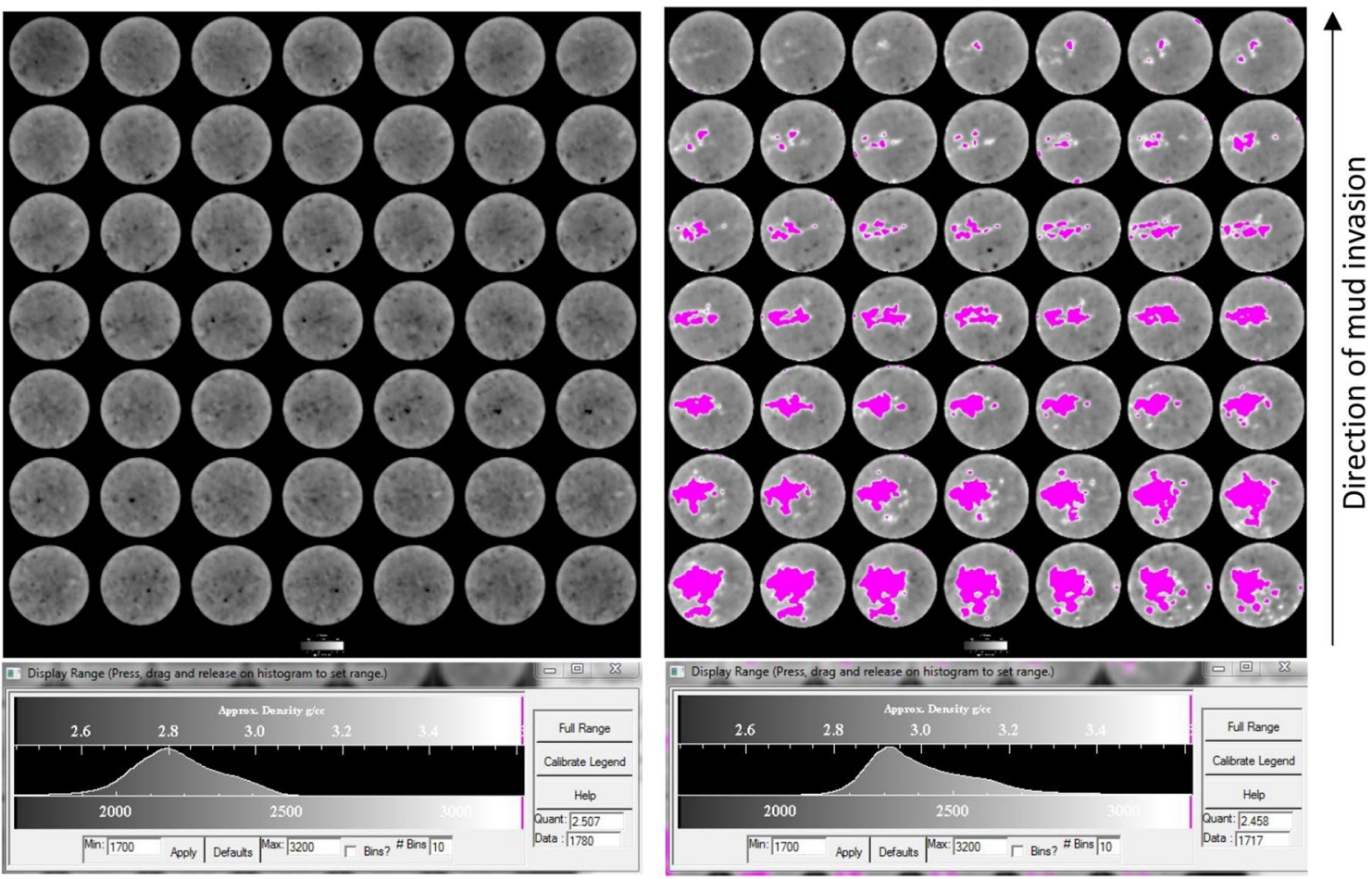

Fig. 5 CT scan of sample 1 showing: (left) pre-filtration-loss slices and (right) post-filtration-loss slices 
barite invasion, wherever it occurs, can be clearly seen as pink spots in the slices. The colored (pink) spots in the post-filtration-loss slices represent the high-density elements whose density fall outside the density distribution of the rock grains (shown in the density/CT number histogram at the bottom of the charts). Only the CT scan images of sample 1 and sample 2 (Fig. 6) are presented here. It is, however, important to mention for the sake of clarity that the CT images of sample 2, sample 3, and sample 4 are identical. The observed pink spots in sample 1 images are due to the invasion of barites into this sample since the drilling fluid applied to this mud has no bridging prevention additive. For reference, the CT images of samples 3 and 4 are presented in "Appendix".

\section{NMR $T_{2}$ relaxation}

In order to be able to accurately and directly relate $T_{2}$ distribution derived from inverse Laplace transform of the multiexponential fit of the CPMG experiments, the inter-echo spacing $(\tau)$ was reduced to as low as $0.1 \mathrm{~ms}$. This optimized parameter also allows the estimation of pore size distribution that covers very small pores including those of filter cakes. For rock sample saturated with a brine, there is a simple equation (Cohen and Mendelson 1982) that relates the $T_{2}$ relaxation values to the pore geometry as given by Eq. (1). The surface relaxivity, $\rho$, is dependent only on the matrix or material lining the pore area. Assuming cylindrical pores, pore size distribution can be estimated from $T_{2}$ distribution using Eq. (2).

$\frac{1}{T_{2}} \approx \rho\left(\frac{S}{V}\right)$

$\frac{1}{T_{2}} \approx \rho\left(\frac{2}{r}\right)$

The $T_{2}$ relaxation distribution of each rock sample at three different stages (100\% water saturation, after mud filtrate invasion plus filter cake deposition, and sample with mud filtrate) is shown for the four experimental cases (Figs. 7, $8,9,10)$. The experimental cases include: (1) filtration loss of mud without filtration control additive (Fig. 7), (2) filtration loss of mud with $1 \%$ filtration control additive (Fig. 8), (3) filtration loss of mud with $2 \%$ filtration control additive (Fig. 9), and (4) filtration loss of mud with 3\% filtration control additive (Fig. 10).

The probability distribution function (PDF) of $T_{2}$ relaxation time shown in Fig. 7A gives an indication of the pore size distribution at three different sample states. The $T_{2}$ relaxation at $100 \%$ water saturation state represents the entire pore size distribution of the sample, and it is shown as the green curve. The blue curve shows the $T_{2}$ relaxation after the sample was subjected to invasion of drilling fluid of type \#1 (shown in Table 2), and filter cake was deposited on the upstream end. The red curve represents the $T_{2}$ relaxation of the sample after
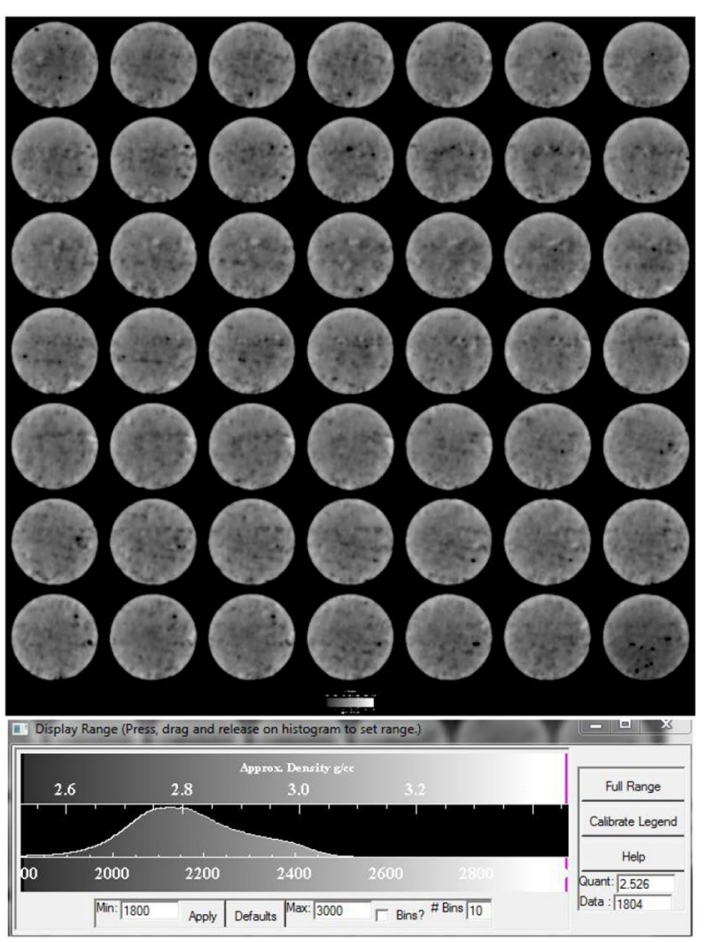

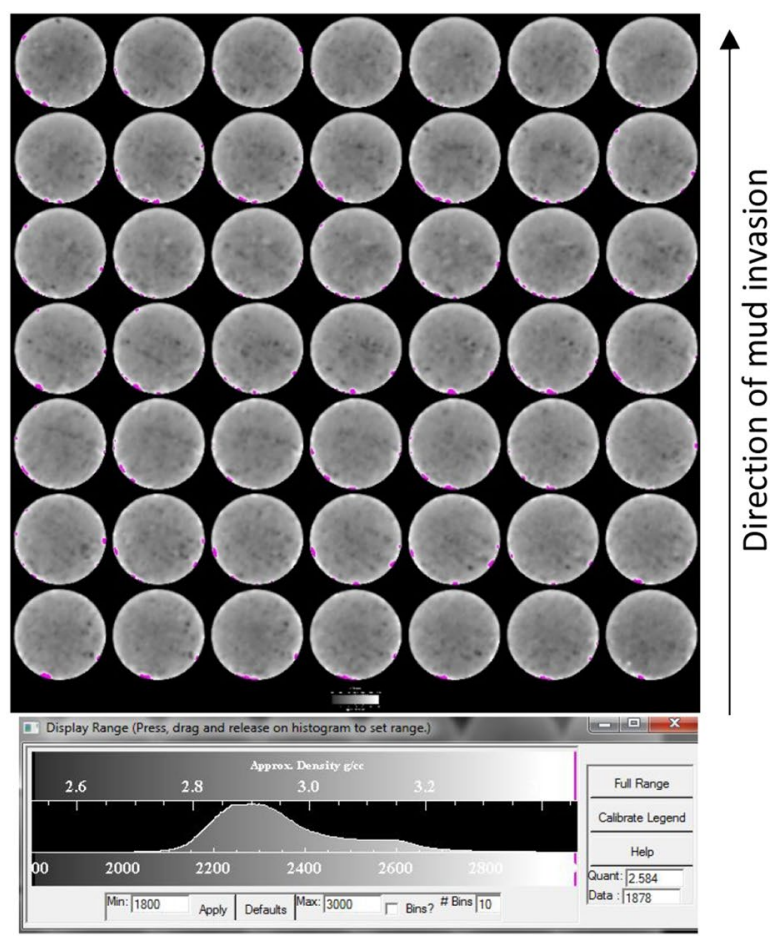

Fig. 6 CT scan of sample 2 showing: (left) pre-filtration-loss slices and (right) post-filtration-loss slices 


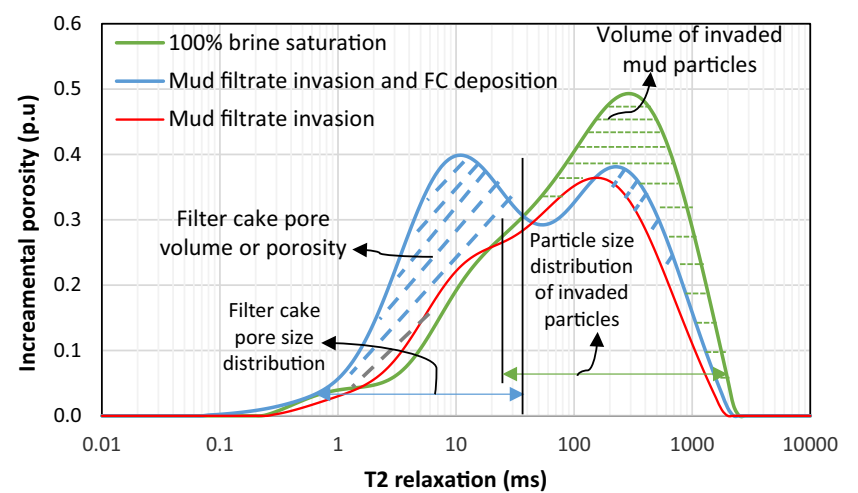

(A)

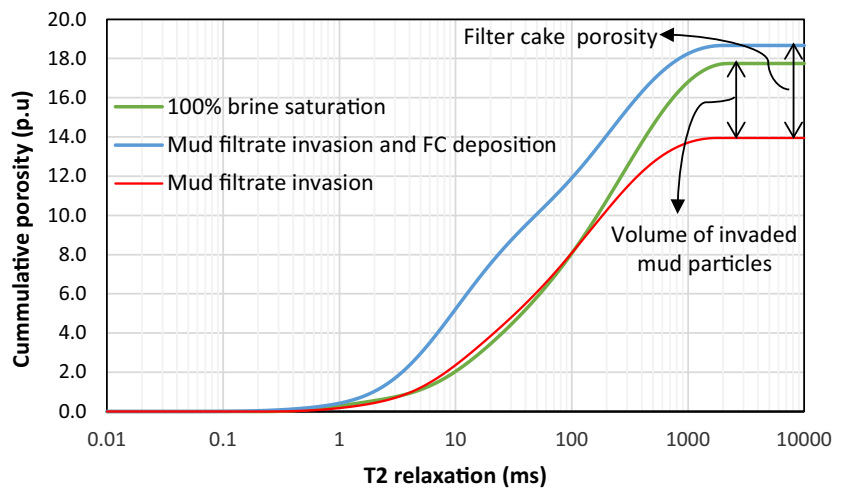

(B)

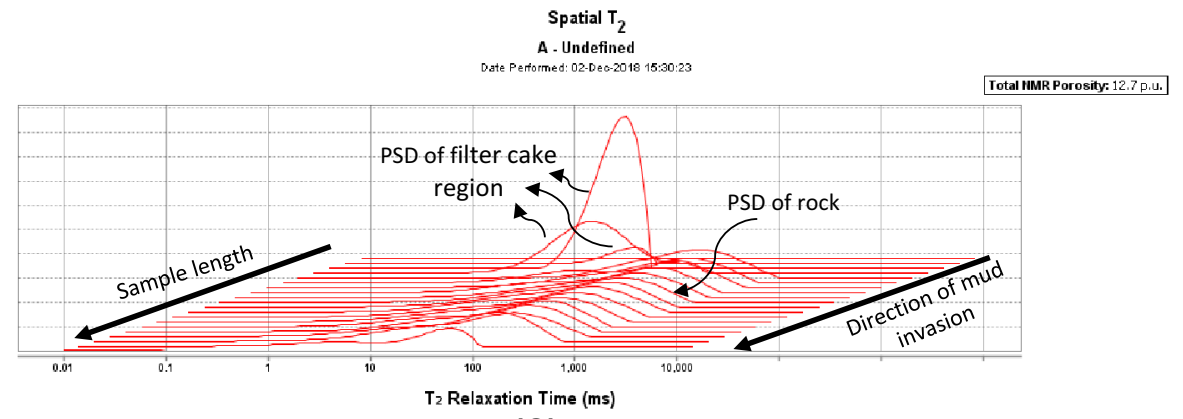

(C)

Fig. 7 Sample $1 \mathrm{~A}$ PDF of NMR $T_{2}$ relaxation showing the pore size distribution at $100 \% \mathrm{KCl}$ saturation (green), after mud invasion and filter cake deposition (blue), and after removal of filter cake. B Cor- responding cumulative pore sizes (porosity) for the different sample states. C The spatial pore size distribution along the sample length

$T_{2}$ of filter cake $=\left[T_{2}\right.$ of invaded drilling fluid

$$
\begin{aligned}
& \left.+T_{2} \text { of water }+T_{2} \text { of filter cake }\right] \\
& -\left[T_{2}\right. \text { of invaded drilling fluid } \\
& \left.+T_{2} \text { of water }\right]
\end{aligned}
$$

Since the invaded drilling fluid contains mainly water and solids, the volume and particle size distribution of the invaded solid particles can be estimated from Eq. (4). The amount of water from the drilling fluid that invaded the rock sample cannot be distinguished from the NMR measurement since an equivalent amount of water is lost from the sample through the outlet of the test cell. An accurate measurement of the effluent water is therefore required to estimate the amount of water loss from the drilling fluid into the rock sample using Eq. (5).

$T_{2}$ of invaded drilling fluid $=(\mathrm{Ai})-($ Aiii $)$

$T_{2}$ of invaded drilling fluid $=\left[T_{2}\right.$ of sample at $100 \%$ water saturation $]-\left[T_{2}\right.$

$$
\text { of invaded drilling fluid }+T_{2} \text { of water] }
$$

Filtration loss (effluent water)

$=$ [volume of invaded solid particles from drilling fluid $]$

+ [volume of invaded water from drilling fluid] where Ai, Aii, and Aiii refer to the sequence of the NMR measurements as illustrated in Fig. 3. 


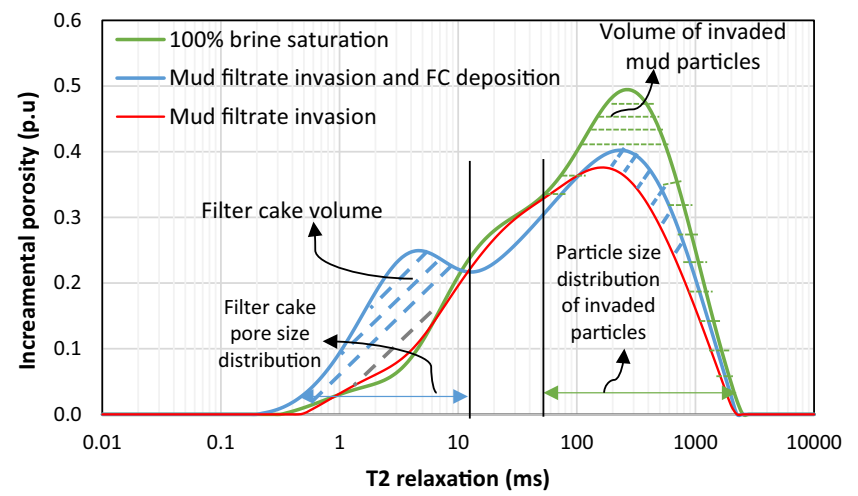

(A)

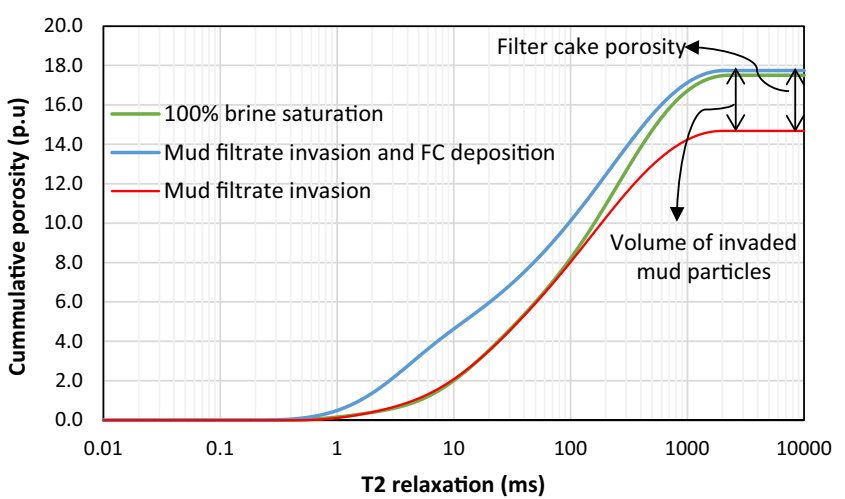

(B)

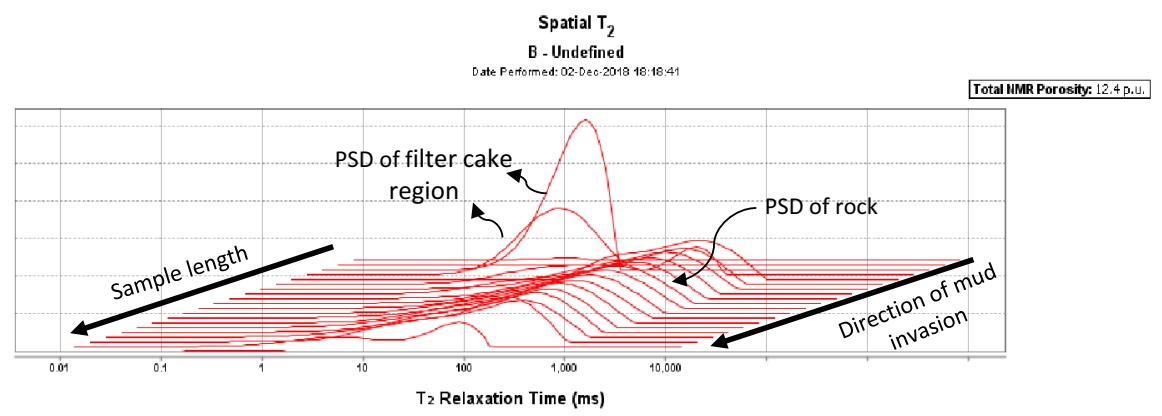

(C)

Fig. 8 Sample 2 (A) PDF of NMR $T_{2}$ relaxation showing the pore size distribution at $100 \% \mathrm{KCl}$ saturation (green), after mud invasion and filter cake deposition (blue), and after removal of filter cake. (B)

Since $T_{2}$ is related to volume by Eq. (2) and also because a standard volume was used to calibrate the $T_{2}$ values, multiple filtration loss properties of the filter cake can be estimated from the $T_{2}$ profile of Eq. (3), such as pore size distribution, porosity, and pore volume of the deposited filter cake. Also, the volume and particle size distribution of the invaded mud particles can be estimated from the $T_{2}$ profile of Eq. (4). The contribution of filter cake in the $T_{2}$ values (blue curve) in the PDF curves is characterized by an increase in the intensity (vertical axis) of the $T_{2}$ signals at lower values, since the filter cake is mostly clay material, which have large volume of tiny surface area. The higher $T_{2}$ values (blue) show a reduction in intensity compared to the $100 \%$ values (green curve). This region (shaded green) corresponds to the pores drained by the invaded mud particles and filtrate. The mud particles are non-hydrogen based and will not give any signal, while the remaining rock water together with the water from invaded mud filtrate gives the NMR signal shown in this high $T_{2}$ range. The net reduction in $T_{2}$ values in this range can then be equated to a corresponding size and volume of the invaded particles.

The PDF curves (Fig. 7a) can be used to estimate size distribution of the filter cake and invaded mud particles, while the CDF curve (Fig. 7b) can be used to estimate volume of the filter cake and invaded mud particles. Figure $7 \mathrm{c}$ shows the PDF curves of $T_{2}$ spatially resolved in the direction of
Corresponding cumulative pore sizes (porosity) for the different sample states. (C) Spatial pore size distribution along the sample length

filtration loss or mud invasion. It can be observed that the $T_{2}$ curves at the filter cake region show a high intensity at the lower range (between 0.2 and $50 \mathrm{~ms}$ ) of the $T_{2}$ values, distinct from those inside the rock, which range between 0.3 and $2000 \mathrm{~ms}$. It can also be observed that multiple layers exist at the filter cake region as seen by the three different curves in the filter cake region. Although each of these layers has similar $T_{2}$ range, the intensity or peaks of the $T_{2}$ vary, indicating that the porosity or pore volume of each layer of filter cake varies from the outermost layer to the innermost layer. The same line of analysis applies for the other experiments shown in Figs. 8, 9 and 10.

Based on the analytical method described for sample 1, the effect of filtration loss additive on mud invasion and formation damage is investigated using the same methodology. In the subsequent figures, the filtration loss additive was added to the mud system in three different concentrations according to the formulation earlier presented in Table 2 . In Fig. 8, the experimental process was repeated, this time adding $1 \%$ concentration of silica (i.e., $1 \mathrm{~g}$ of the filtration loss additive in $100 \mathrm{ml}$ of mud) to the same drilling fluid that is used in Fig. 7. What is immediately observed in Fig. 8 is the volume and size of the filter cake and invaded particles. The pore size distribution of the filter cake is also drastically reduced. In order to establish what optimum concentration 


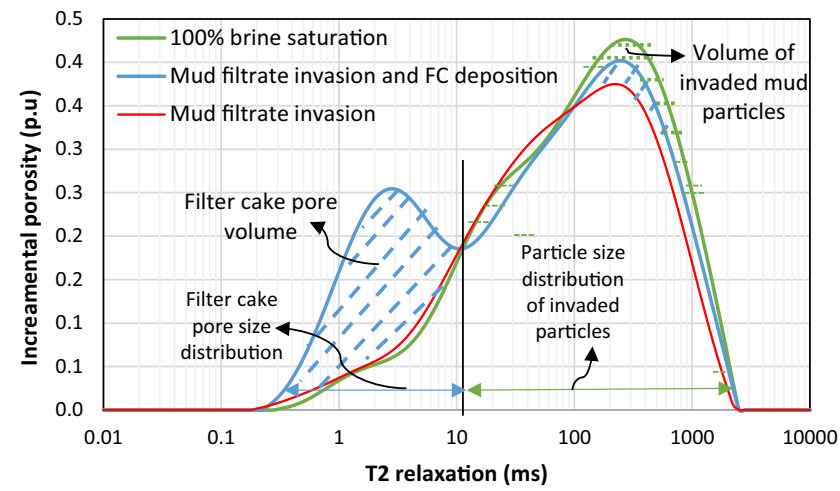

(A)

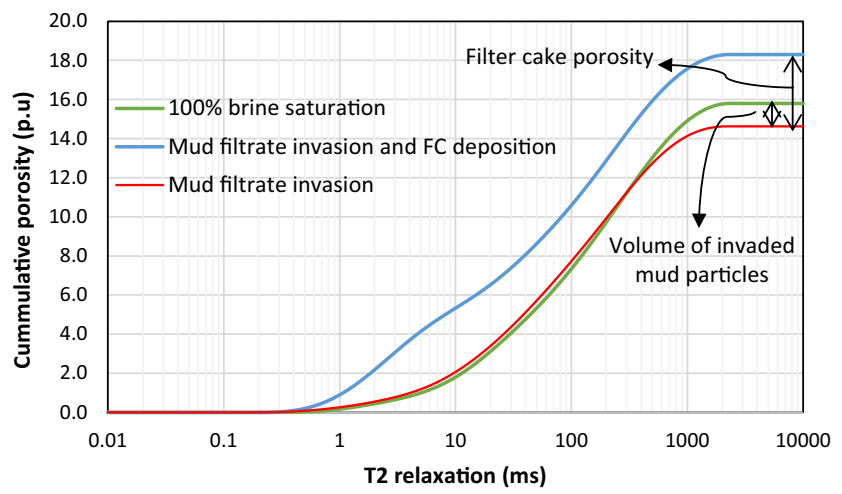

(B)

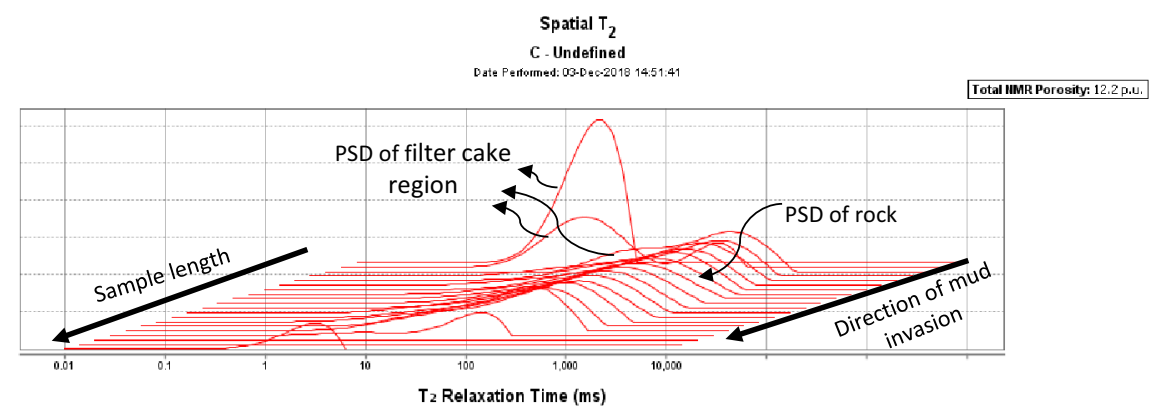

(C)

Fig. 9 Sample 3 (A) PDF of NMR $T_{2}$ relaxation showing the pore size distribution at $100 \% \mathrm{KCl}$ saturation (green), after mud invasion and filter cake deposition (blue), and after removal of filter cake. B
Corresponding cumulative pore sizes (porosity) for the different sample states. C Spatial pore size distribution along the sample length

where $\rho_{\mathrm{f}}$ and $\rho_{\mathrm{g}}$ are the fluid and the grain densities, respectively, and $\alpha$ is measured using Eq. (7).

The wet and dry weights of the filter cake were measured using a high-resolution weight balance (resolution of $0.001 \mathrm{~g}$ ). The dry weight was obtained after drying the filter cake in an oven at a temperature of $100{ }^{\circ} \mathrm{C}$ for $24 \mathrm{~h}$.

Figure 12 compares the filtration loss (effluent measurement from a graduated test tube) for the different concentrations of additives. The same trend of observation was observed. The largest filtration loss $\left(3.6 \mathrm{~cm}^{3}\right)$ occurred in $0 \%$ concentration. One percentage additive concentration has the lowest filtration loss $\left(2.3 \mathrm{~cm}^{3}\right)$, while $2 \%$ and $3 \%$ additive concentrations both have a filtration loss of $2.7 \mathrm{~cm}^{3}$. Using the material balance of Eq. (5), the components of the filtration loss were estimated as shown in Fig. 13 (which include the volume of invaded solid particles and the volume of invaded). It can be observed that, as the additive concentration increased, the volume fraction of invaded particles decreased, while the volume fraction of the invaded water increased. The minimum solid invasion $\left(0.8 \mathrm{~cm}^{3}\right)$ was obtained at $2 \%$ additive concentration. The average filter cake thickness for the different additives concentration as measured by a digital caliper is shown in Fig. 14. The filter cake thickness does not give a clear $\alpha=\frac{\text { net wet weight of the filter cake }}{\text { net dry weight of the filter cake }}-1$ $\emptyset_{c}=\frac{\alpha}{\alpha+\frac{\rho_{\mathrm{f}}}{\rho_{\mathrm{g}}}}$ and gravimetric methods, respectively. Dewan and Chenevert (2001) published the following relation, Eq. (6), to determine filter cake porosity by gravimetric method.

$$
\text { net dry weight of the filter cake }
$$

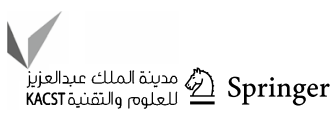




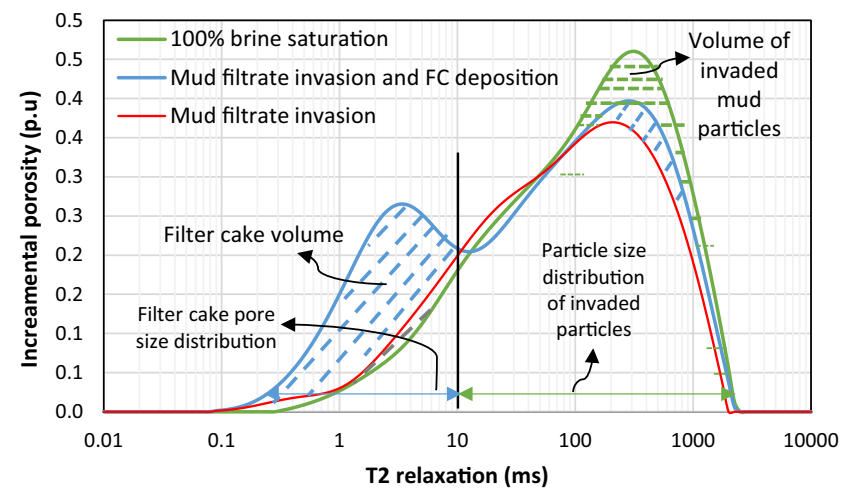

(A)

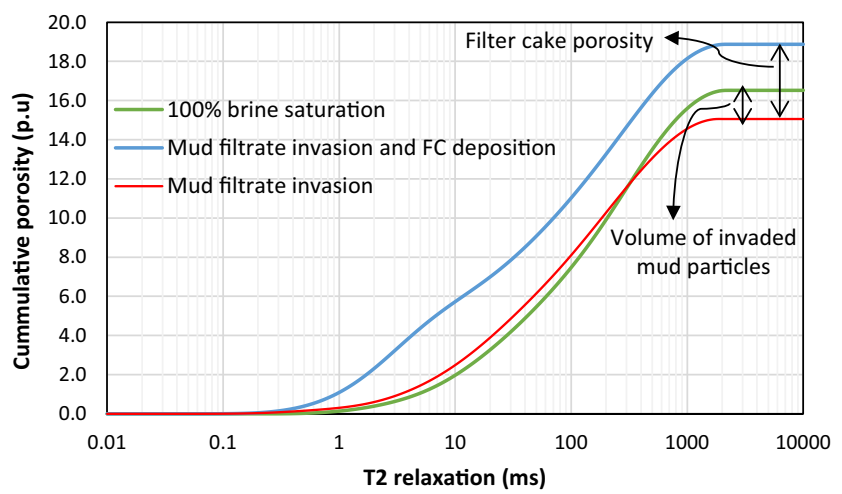

(B)

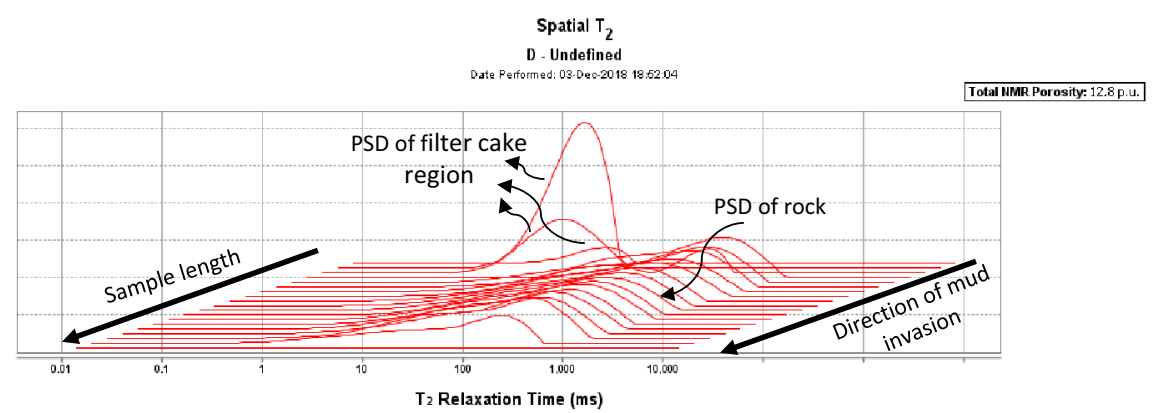

(C)

Fig. 10 Sample 4 A PDF of NMR $T_{2}$ relaxation showing the pore size distribution at $100 \% \mathrm{KCl}$ saturation (green), after mud invasion and filter cake deposition (blue), and after removal of filter cake. B Cor-

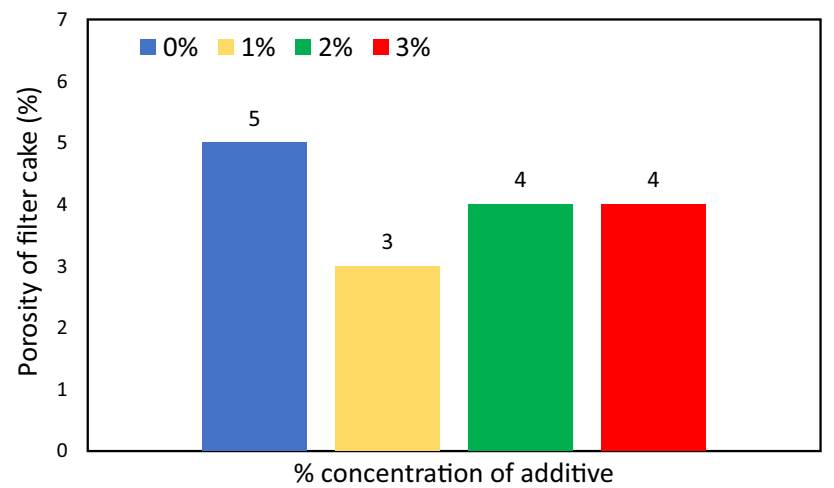

Fig. 11 Porosity of filter cake as a function of additive concentration

relationship between filtration loss and additive concentration. This is in part due to the inability to measure filter cake thickness at high accuracy, since the cakes have to be dried before measurement. Also, the thickness of the cake is not uniform across its circumference.

A surface relaxivity value of $\rho_{2}=6.3 \mu \mathrm{m} / \mathrm{s}$ was reported for shale (Josh et al. 2012), while for sandstone, a commonly cited literature value of $\rho 2$ is approximately $10-11 \mu \mathrm{m} / \mathrm{s}$ (Straley et al. 1997). Applying these surface responding cumulative pore sizes (porosity) for the different sample states. C Spatial pore size distribution along the sample length

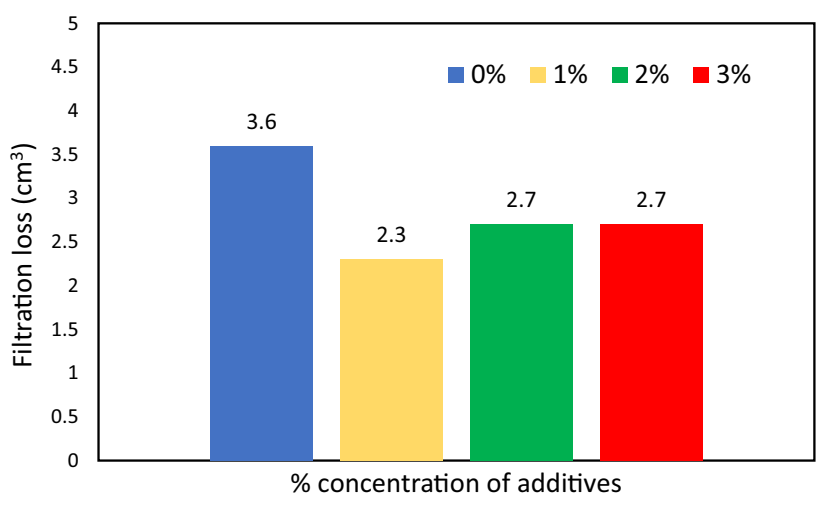

Fig. 12 Filtration loss as a function of additive concentration

relaxivity values to Eq. (2), the pore size distribution of each filter cake and the particle size distribution of the invaded solid particles was estimated as shown in Table 3.

\section{Conclusion}

A NMR methodology has been presented that allowed filtration loss property of drilling fluid and drilling fluid formation damage to be evaluated. A filtration loss control additive was 


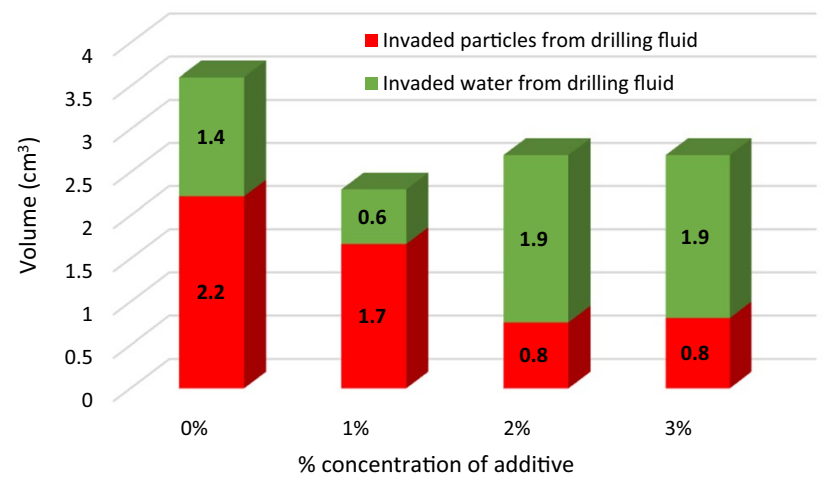

Fig. 13 Volume of invaded solid particles and water as a function of additive concentration

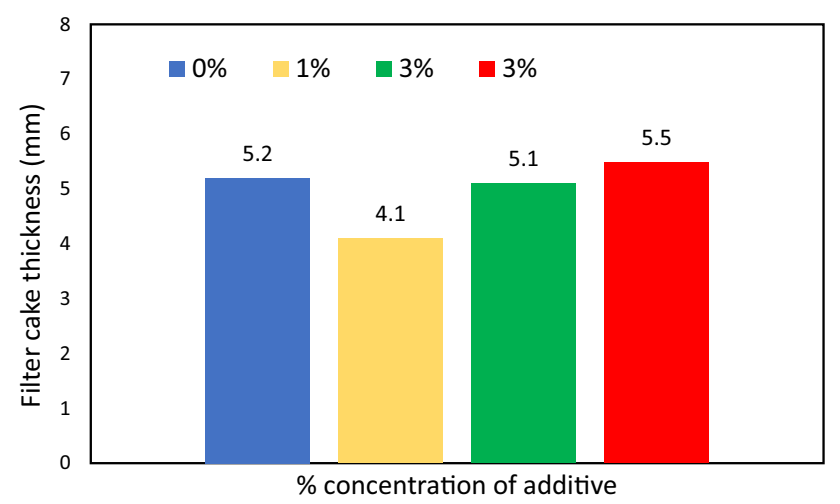

Fig. 14 Filter cake thickness as a function of additive concentration

added in different concentrations to three different drilling fluids, while a reference drilling fluid has no filtration additive added. The filtration loss behavior of the four drilling fluids was then evaluated using a new NMR methodology. A CT scan was also conducted to verify this methodology.

The NMR technique discussed in this paper is based on water-based drilling fluid. For an oil-based drilling fluid, a modified NMR procedure will be required to discern the $T_{2}$ values of water from $T_{2}$ values of oil. Furthermore, the methodology will be more complex when the rock samples are conditioned to a real reservoir subsurface condition such as oil or mixed wettability system containing oil at irreducible water saturation. In such scenario, the drilling fluid will have to be doped with contrast agents such that they can be differentiated from the in situ rock fluid after filtration loss. It is not possible to identify barite or the identity of the invaded particles by using only NMR. However, CT scan allows the density of the invading solids to be evaluated, which made it possible to conclude whether barite invaded the rock samples or not. Nonetheless, the NMR method presented here has many advantages over other methods as summarized below.

1. The pore volume, pore size distribution, and porosity of filter cake can be estimated. The filter cake porosity values measured by NMR are in good agreement with the porosity values measured by gravimetric method.

2. The volume of invading particles and the particle size distribution of the invaded particles, which corresponds to the pore size distribution of the plugged pores, were measured.

3. The volume fraction of water and solids can be estimated from the mud filtrate or filtration loss.

4. The presented NMR method has the potential to mature for implementation in oil and gas wells such that in situ and real-time evaluation of drilling fluid performance and formation damage can be conducted.

Acknowledgements The authors are grateful to the College of Petroleum Engineering and Geosciences at King Fahd University of Petroleum and Minerals for the research support. Rahul Salin Babu and Syed Rizwanullah are acknowledged for their support in running the experiments. We thank the anonymous reviewers for their critical review, which without doubt improved the quality of this paper.

Open Access This article is distributed under the terms of the Creative Commons Attribution 4.0 International License (http://creativeco mmons.org/licenses/by/4.0/), which permits unrestricted use, distribution, and reproduction in any medium, provided you give appropriate credit to the original author(s) and the source, provide a link to the Creative Commons license, and indicate if changes were made.

\section{Appendix}

The CT images of sample 3 and sample 4 are shown in Figs. 15 and 16, respectively. As noted earlier, there are no observed pink spots (representing invading particles) in the

Table 3 Pore size distribution ( $T_{2}$ relaxation time) of filter cake and particle size distribution of invaded solids

\begin{tabular}{|c|c|c|c|c|c|}
\hline Sample ID & $\begin{array}{l}\text { Conc. of additive } \\
(\%)\end{array}$ & $\begin{array}{l}T_{2} \text { distribution of } \\
\text { FC (ms) }\end{array}$ & $\begin{array}{l}\text { Pore size distribution of } \\
\text { filter cake }(\mu \mathrm{m})\end{array}$ & $\begin{array}{l}T_{2} \text { distribution of invaded } \\
\text { particles }(\mathrm{ms})\end{array}$ & $\begin{array}{l}\text { Particle size distribution } \\
\text { of invaded particles }(\mu \mathrm{m})\end{array}$ \\
\hline 1 & 0 & $0.2-50$ & $0.00252-0.63$ & $51-2500$ & $1.02-50$ \\
\hline 2 & 1 & $0.2-10$ & $0.00252-0.126$ & $11-2500$ & $0.22-50$ \\
\hline 3 & 2 & $0.2-10$ & $0.00252-0.126$ & $11-2500$ & $0.22-50$ \\
\hline 4 & 3 & $0.1-10$ & $0.00126-0.126$ & $11-2500$ & $0.22-50$ \\
\hline
\end{tabular}



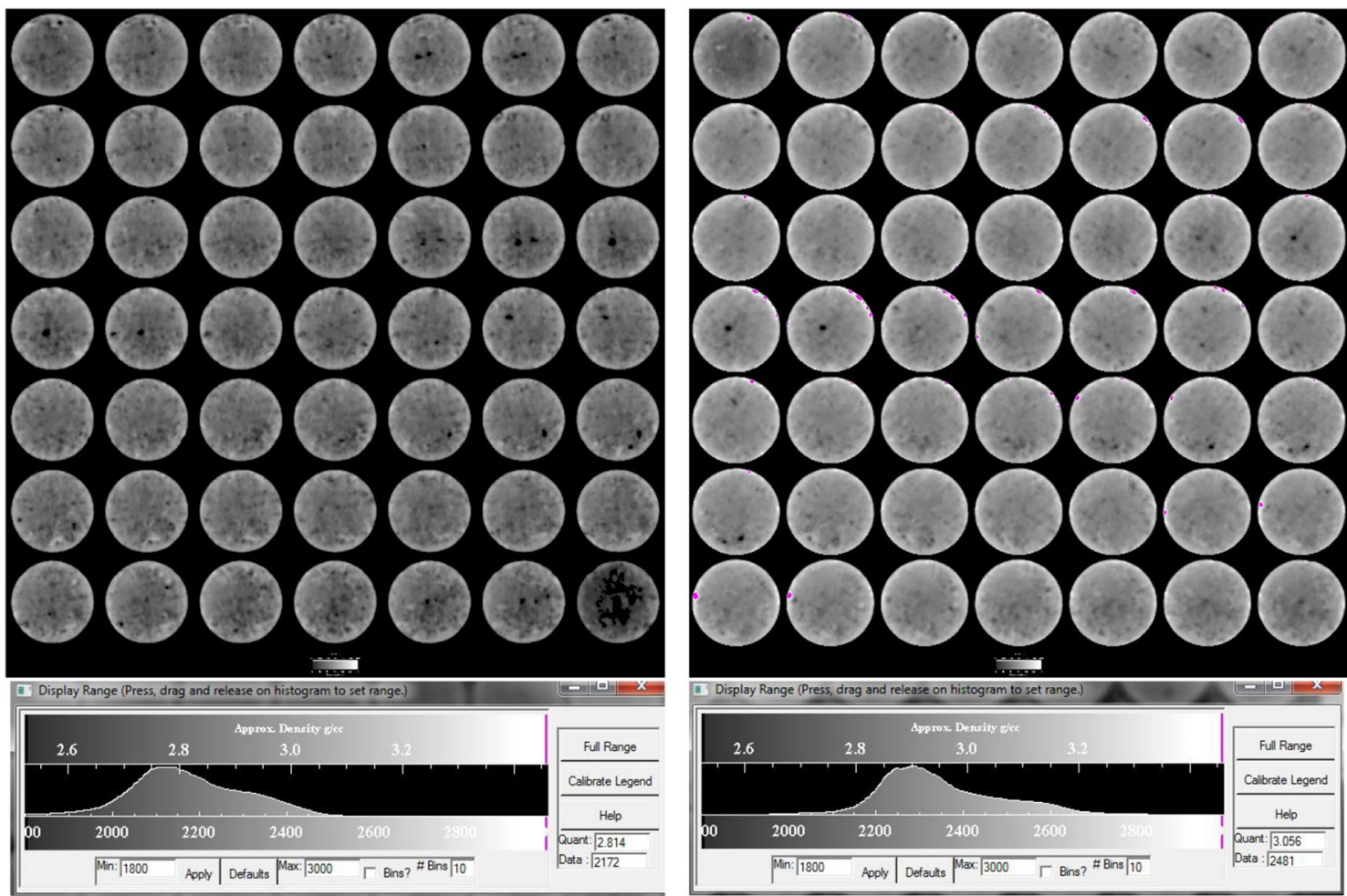

Fig. 15 CT scan of sample 3 showing: (left) pre-filtration-loss slices and (right) post-filtration-loss slices
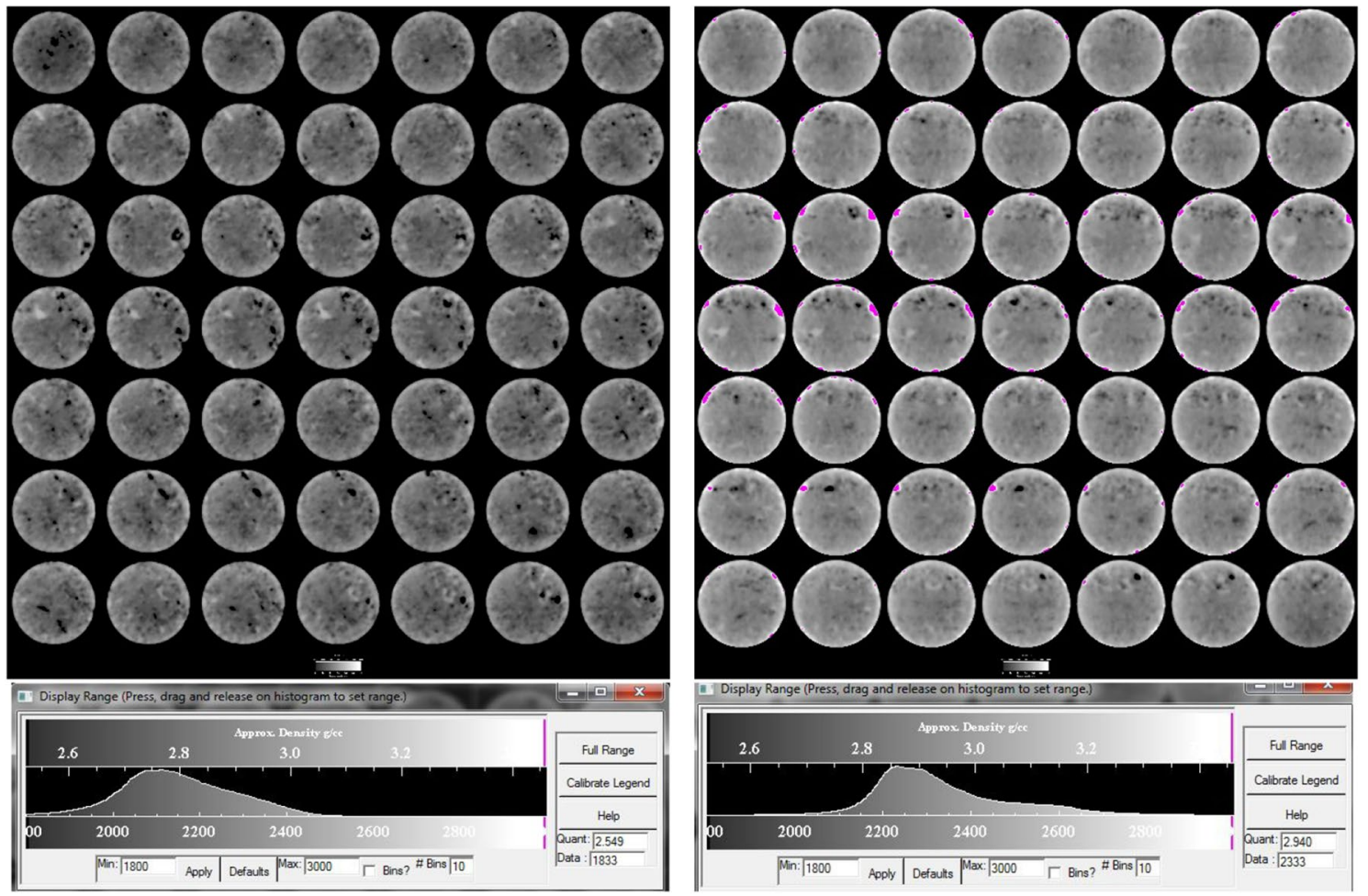

Fig. 16 CT scan of sample 4 showing: (left) pre-filtration-loss slices and (right) post-filtration-loss slices

1

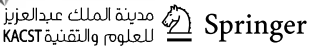


post-filtration-loss slices of samples 2, 3, and 4 as in sample 1 images. The additives added to the drilling fluid used in these samples prevented the invasion of barites into the rock matrix. Note that the pink patches around the circumferences of some of the post-filtration-loss slices are remnant of the mud particles around the samples during scanning. Invaded particles will appear inside the slides as in Fig. 5.

\section{References}

Al-Yaseri Ahmed Z, Lebedev Maxim, Vogt Sarah J, Johns Michael L, Barifcani Ahmed, Iglauer Stefan (2015) Pore-scale analysis of formation damage in Bentheimer sandstone with in situ NMR and micro-computed tomography experiments. J Petrol Sci Eng 129:48-57. https://doi.org/10.1016/j.petrol.2015.01.018

Amaefule JO, Kersey DG, Norman DL, Shannon PM (1988) Advances in formation damage assessment and control strategies. In: CIM paper no. 88-39-65. Proceedings of the 39th annual technical meeting of petroleum society of CIM and Canadian Gas Processors Association, Calgary, Alberta, 12-16 June 1988

Bageri BS, Al-Mutairi SH, Mahmoud MA (2013) Different techniques for characterizing the filter cake. Soc Pet Eng 1:1. https://doi. org/10.2118/163960-MS

Bennion DB, Thomas FB, Bennion DW (1991) Effective laboratory coreflood tests to evaluate and minimize formation damage in horizontal wells. Presented at the 3rd international conference on horizontal well technology, Nov 1991, Houston, TX

Byrne MT, Spark ISC, Patey ITM, Twynam AJ (2000) A laboratory drilling mud overbalance formation damage study utilising cryogenic SEM techniques. SPE 58738, Presented at the SPE international symposium on formation damage control held in Lafayette, Louisiana, 23-24 Feb 2000

Carr HY, Purcell EM (1954) Effects of diffusion on free precession in nuclear magnetic resonance experiments. Phys Rev 94:630-638. https://doi.org/10.1103/PhysRev.94.630

Civan F (2007) Reservoir formation damage fundamentals, modeling, assessment and mitigation, 2nd edn. Gulf Publishing Company, Houston, p 1114

Civan F (2016) Civan reservoir formation damage, 3rd edn. Elsevier, Oxford

Cohen MH, Mendelson KS (1982) Nuclear magnetic relaxation and the internal geometry of sedimentary rocks. J Appl Phys 53(2):1127. https://doi.org/10.1063/1.330526

Dewan JT, Chenevert ME (2001) A model for filtration of water-base mud during drilling: determination of mudcake parameters. Soc Petrophys Well Log Anal 42(03):237-250

Fischer S, Zemke K, Liebscher A, Wandrey M (2011) Petrophysical and petrochemical effects of long-term $\mathrm{CO}_{2}$-exposure experiments on brine-saturated reservoir sandstone. Energy Procedia 4:4487-4494

Gabriel GA, Inamdar GR (1983) An experimental investigation of fines migration in porous media. SPE-12168. Presented at the SPE annual technical conference and exhibition, San Francisco, California, 5-8 Oct (1983)

Godinho JRA, Chellappah K, Collins I, Ng P, Smith M, Withers PJ (2019) Time-lapse imaging of particle invasion and deposition in porous media using in situ X-ray radiography. J Petrol Sci Eng 177:384-391. https://doi.org/10.1016/j.petrol.2019.02.061

Green J, Cameron R, Patey I, Nagassar V, Quine M (2013) Use of micro-CT scanning visualisations to improve interpretation of formation damage laboratory tests including a case study from the South Morecambe field. SPE 165110, Presented at the SPE European formation damage conference, Noordwijk, The Netherlands, 5-7 June 2013

Josh M, Esteban L, Delle Piane C, Sarout J, Dewhurst DN, Clennell MB (2012) Laboratory characterisation of shale properties. J Petrol Sci Eng 88-89:107-124. https://doi.org/10.1016/j.petro 1.2012.01.023

Kandarpa V, Sparrow JT (1981) A useful technique to study particle invasion in porous media by backscattered electron imaging. SPE 10134, Presented at the SPE 56th annual fall technical conference and exhibition, San Antonio, Texas, Oct 5-7, 1981

Krilov Z, Steiner I, Goricnik B, Wojtanowicz AJ, Cabrajac S (1991) Quantitative determination of solids invasion and formation damage using CAT scan and barite suspensions. SPE 23102, Presented at the SPE Offshore Europe Conference, UK, Aberdeen, 3-6 Sept 1991

Meiboom S, Gill D (1958) Modified spin-echo method for measuring nuclear relaxation times. Rev Sci Instrum 29:688-691. https://doi. org/10.1063/1.1716296

Offenbacher M, Luyster M, Gray L, He W, Leonard R, Stephens M (2013) Return permeability: when a single number can lead you astray in fluid selection. SPE-165106, Presented at the SPE European formation damage conference, Noordwijk, The Netherlands, 5-7 June 2013

Seright RS, Prodanovic M (2006) Lindquist WB X-ray computed microtomography studies of fluid partitioning in drainage and imbibition before and after gel placement: disproportionate permeability reduction. Soc Pet Eng J 11(2):159-170. https://doi. org/10.2118/89393-PA

Straley C, Rossini D, Vinegar HJM, Tutunjian PN, Morriss CE (1997) SCA paper 9494, Society of Core Analysts (1995), or The Log Analyst, 38, p 84

Tran TV, Civan F, Robb ID (2010) Effect of permeability impairment by suspended particles on invasion of drilling fluids. IADC/SPE 133724, Presented at the IADC/SPE Asia Pacific drilling technology conference and exhibition, Vietnam, Ho Chi Minh, 1-3 Nov 2010

Publisher's Note Springer Nature remains neutral with regard to jurisdictional claims in published maps and institutional affiliations. 